\title{
Preparation of dichloride of carbon
}

\section{Regnault}

To cite this article: M. Regnault (1839) Preparation of dichloride of carbon, Philosophical Magazine Series 3, 14:91, 473-473, DOI: $10.1080 / 14786443908649790$

To link to this article: http://dx.doi.org/10.1080/14786443908649790

册 Published online: 01 Jun 2009.

Submit your article to this journal 준

Џll Article views: 2

Q View related articles $₫$ 
by Professors Gauss and Weber, being the First Annual Report of the Magnetic Association. An introduction, from the pen of Gauss, on the Irregular Variations of the Terrestrial Magnetic Force, is succeeded by "Remarks on the Arrangement of Magnetical Observatories, and Description of the Instruments to be placed in them," by Weber; which is followed by a minute account of the "Method to be pursued during the terms of Observation," by Gauss. This is succeeded by an "Extract," also by Gauss, " from the daily Observations of Magnetic Declination during three years at Göttingen," and a "Description of a small portable apparatus for measuring the absolute intensity of Terrestrial Magnetism, and Explanations of the six graphical Representations and of the Table of Results." Our readers will remember the Report to the Council of the Royal Society of a Joint Committee of Physics and Meteorology " on the establishment of fixed Magnetic Observatories and the equipment of an Antarctic Expedition for Magnetic Observations," which appeared in the Philosophical Magazine for February last, and to which we may refer those who may not have already become acquainted with the value and bearings of the work of Gauss and Weber, which now first appears in the English language.

The Part, which is illustrated by Ten Engravings, also contains a highly valuable memoir by Professor Heinrich Rose on the Combinations of Ammonia with Carbonic Acid; and another by Melloni on the Polarization of Heat.

PRE PARATION OF DICHLORIDE OF CARBON. BY M. REGNAUIT.

M. Regnault prepared the proto-chloride of carbon, which, however, according to French equivalents, is described as $\mathrm{CCl}^{2}$, according to Faraday's process; he states that he found its boiling point to be $248^{\circ}$ instead of $170^{\circ}$, as mentioned by Faraday; the density of the vapour he ascertained to be $5 \cdot 8$, and therefore he considers it as composed of $\mathrm{C}^{4} \mathrm{Cl}^{8}$, and it belongs, he says, to the series of chloride of aldehyde, - that is, to a series of which it contains only two out of three elements, - but then this is explained by the doctrine of substitutions- " C"est l'hydrogène bicarboné $\mathrm{C}^{4} \mathrm{H}^{8}$, dans lequel l'hydrogène est remplacé par son équivalent de chlore." It appears to me that it would be quite as consistent with sound philosophy, and attended with the additional advantage of somewhat extending the doctrine of substitutions, if we were to say, that water belongs to the series of sulphurets of mercury in which the sulphur is replaced by its equivalent of oxygen, and the mercury by its equivalent of hydrogen.

$M$. Regnault appears, however, to have succeeded in preparing the dichloride of carbon, a specimen of which, as an accidental product, was examined by Mr. Faraday and myself. He procured it by repeatedly passing the proto-chloride through a tube heated to redness; the dichloride condenses in the coldest parts of the tube in very fine silky needles, which are to be separated by æther; when resublimed it is quite pure. This substance is nearly inodorous ; it is difficult to hit upon the exact degree of heat for its preparation; if it be too great, the decomposition is complete and charcoal is deposited.-R.P.An. de Ch. et de Ph. lxx., 105. 
DELVAUXENE-A NEW PHOSPHATE OF IRON.

This mineral was first found in 1793, at Berneau, near Visé ; it occurs in brittle reniform masses, its texture is compact, and its fraeture perfect conchoidal. It is opake or only slightly translucent on the edges of thin fragments; its lustre is sometimes resinous; sometimes it is dull ; colour blackish or reddish brown, but sometimes yellowish brown; the powder is of a yellowish brown, and the finer the brighter. Its hardness is intermediate as to that of calcareous spar and sulphate of lime: specific gravity $1 \cdot 85$. When heated in a flask it yields much water, and loses 42 per cent. of water when heated to redness. Before the blow-pipe it decrepitates and fuses into a grey very magnetic globule of iron.

With borax on a platina wire, in the reducing flame, a bottlegreen globule is obtained, and in the oxidating flame a globule, which is brownish while hot, and becomes green on cooling. In water it falls to pieces, effervesces and gelatinizes in hydrochloric acid, forming a brownish orange solution; the nitric solution gives a white precipitate with nitrate of lead, and a blue one with ferrocyanide of potassium. 'This mineral was first found in a lead mine, but it has since occurred in a stone-quarry near the same place. M. Dumont analyzed both varieties-1 st, reddish brown, 2nd, brownish black-the results were

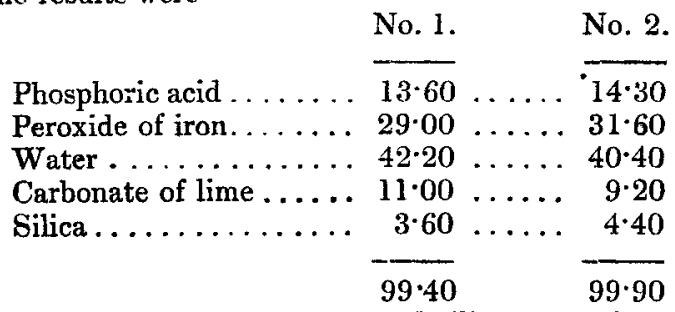

Neglecting the carbonate of lime and silica, this mineral is a di. phosphate of peroxide of iron +6 eqs. of water; the phosphate of iron of the Isle of France, analysed by Laugier, differs from the above in containing only half the quantity of water.

The name of Delvauxene was given to this mineral by M. Dumont from that of its discoverer M. Delvaux.-L'Institut, No. 276.

ON THE USE OF AMMONIA IN FIXING PHOTOGRAPHS. BY J. C. CONSTABLF, ESQ.

To the Editors of the Philosophical Magazine.

\section{Genthemen,}

Mr. Fox Talbot, in his paper on photogenic drawing, states, that he did not succeed in preserving the drawings by means of ammonia; some experiments which I have made lead to a different result. I find that the drawings, after being soaked for some minutes in a moderately strong solution of ammonia and then washed in clean water, withstand the action of the light perfectly, and indeed are improved by it: for the first action of the ammonia is to make the dark parts of a reddish hue, which, on exposure to the light, become again of a dark colour, the light parts being unaffected. This mode 